\title{
Leukotriene receptor antagonist therapy
}

\author{
O J Dempsey
}

\begin{abstract}
Leukotriene receptor antagonists (LTRA) are a new class of drugs for asthma treatment, available in tablet form. Their unique mechanism of action results in a combination of both bronchodilator and anti-inflammatory effects. While their optimal place in asthma management is still under review, LTRA represent an important advance in asthma pharmacotherapy.

(Postgrad Med F 2000;76:767-773)
\end{abstract}

Keywords: leukotriene receptor antagonist; asthma; montelukast; zafirlukast

Asthma and Allergy

Research Group, Department of Clinical Pharmacology and Therapeutics, Ninewells Hospital and Medical School, University of Dundee, Dundee DD1 9SY, UK O J Dempsey

Correspondence to: Dr Dempsey dempseyowen@hotmail.com

Submitted 6 March 2000 Accepted 19 April 2000

Leukotriene receptor antagonists (LTRA) are a new class of drugs for asthma treatment, available in tablet form. ${ }^{12}$ Their unique mechanism of action results in a combination of both bronchodilator and anti-inflammatory effects. While their optimal place in asthma management is still under review, LTRA represent an important advance in asthma pharmacotherapy. In this article I provide a brief overview of evidence supporting their use in patients with chronic asthma, focusing on two leukotriene receptor antagonists, montelukast and zafirlukast, currently licensed for use in the United Kingdom.

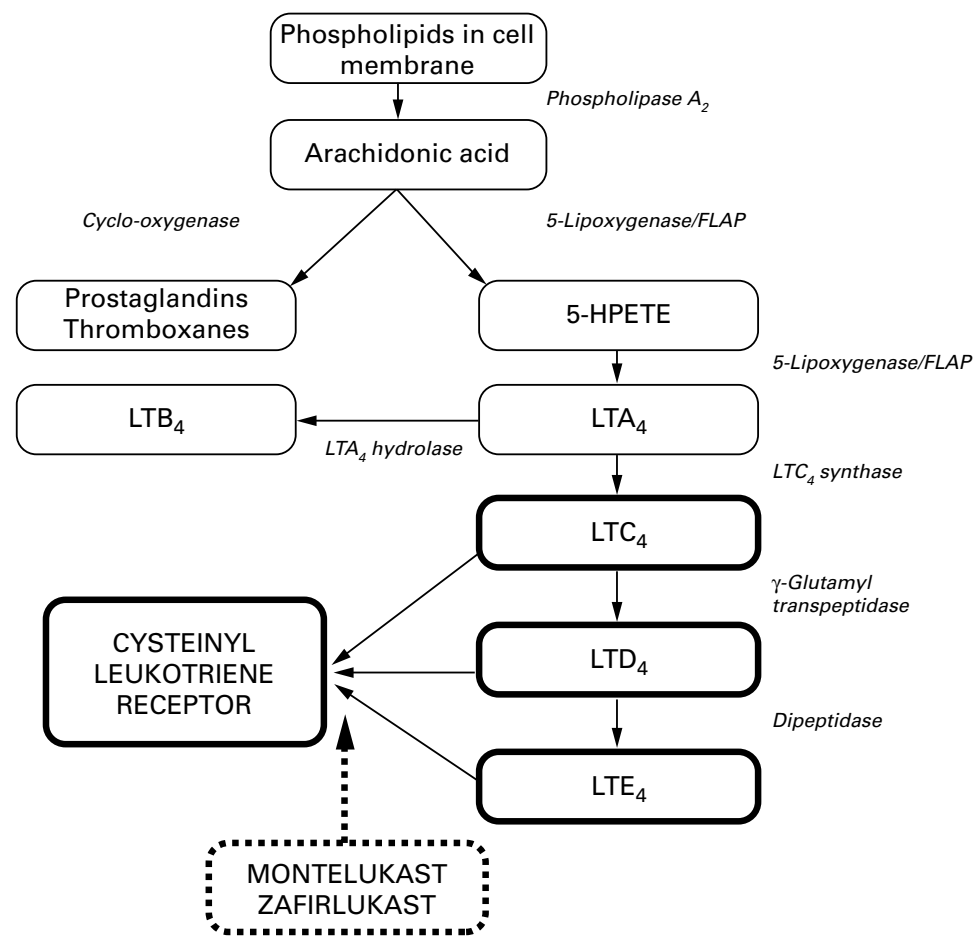

Figure 1 Arachidonic acid metabolism. Cysteinyl leukotrienes ( TTC $_{4}$, LTD $\left._{4}, \mathrm{LTE}_{4}\right)$ interact with a specific receptor, which is blocked by antagonists such as montelukast or zafirlukast. FLAP, 5-lipoxygenase activating protein; HPETE,

5-hydroxyperoxyeicosatetraenoic acid.
Box 1: Biological effects of cysteinyl leukotrienes

- Bronchoconstriction (100-10000 times more potent than histamine).

- Bronchial smooth muscle hyperresponsiveness, for example to allergen.

- Inflammatory cell recruitment, for example eosinophils.

- Vascular permeability (leading to tissue oedema and airflow obstruction).

- Mucus formation (leading to further airflow obstruction).

\section{Methods}

Fully published papers and review articles between 1966 and January 2000 were sought using appropriate index terms and the National Library of Medicine's computerised search service (providing access to Medline, PreMedline, and other related databases). Studies published only in abstract form (and thus subject to less rigorous peer review) are not discussed.

\section{Background}

The term "slow reacting substance of anaphylaxis" (SRS-A), coined by Brocklehurst in 1960 , is still familiar to many physicians. ${ }^{3}$ The chemical structure of SRS-A, however, was not identified until 1979 by Samuelsson and colleagues, who discovered that it consisted of a family of biologically active fatty acids derived from arachidonic acid metabolism in many cells, including eosinophils, mast cells, and lymphocytes (fig 1). ${ }^{5}$ The term "leukotriene" is apt, given their synthesis in leucocytes and their chemical structure (containing three conjugated double bonds, that is, a triene). Of particular importance in the patient with asthma are leukotrienes $\mathrm{C}_{4}, \mathrm{D}_{4}$, and $\mathrm{E}_{4}$. As these contain the amino acid residue cysteine, they are sometimes referred to collectively as the cysteinyl leukotrienes.

Cysteinyl leukotrienes are important biological mediators in asthma, interacting with at least one specific receptor in the lungs, which has now been fully identified, ${ }^{6}{ }^{7}$ leading to various important biological effects (box 1). Of these, potent bronchoconstriction is well recognised, but they also have a variety of effects that are proinflammatory. ${ }^{8}$ Thus leukotrienes are capable of inducing several key features of asthma. Furthermore, studies have shown that leukotrienes are produced in excessive quantities in patients with asthma, reinforcing the view that they are important biological mediators. $^{9}$ 

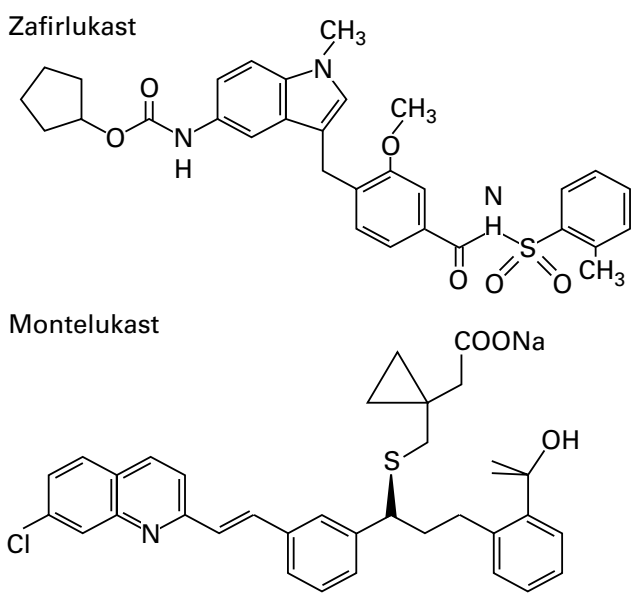

Figure 2 Structure of zafirlukast (top) and montelukast (bottom).

Interestingly, inhaled or oral corticosteroids have not been shown to attenuate leukotriene production significantly in vivo. This led to interest in the development of specific leukotriene modifying asthma drugs, which might confer additional benefits even in patients already receiving an optimal dose of inhaled corticosteroid. $^{10}$ Several drug classes were developed, affecting various sites in the leukotriene biosynthetic cascade, of which the most successful have been receptor antagonists.

\section{Leukotriene receptor antagonists}

STRUCTURE

Montelukast and zafirlukast are two of the most commonly prescribed LTRA available worldwide. Their structures are shown in fig 2 .

\section{PRESCRIBING INFORMATION}

Prescribing information is given in table $1 .{ }^{11}{ }^{12}$ Montelukast and zafirlukast share some pharmacokinetic properties including rapid oral absorption (three hours to peak plasma concentrations), near maximal (99\%) plasma protein binding, and, after extensive hepatic biotransformation, excretion principally in the bile. The terminal half lives of the two drugs are five and 10 hours, respectively.

Zafirlukast can inhibit the hepatic microsomal cytochrome P450 isoenzymes CYP2C9 and CYP3A at therapeutic concentrations, which clinically may result in drug interactions with other drugs using these enzymes. Similarly, as montelukast is metabolised by CYP 3A4, caution should be exercised, particularly in children when montelukast is coadministered with inducers of this enzyme, as listed in table 1.

Another clinically relevant point is that co-administration of food with zafirlukast can reduce oral bioavailability by approximately $40 \%$, which means that patients should avoid taking this preparation soon before or after food (see table 1). This may have implications for patient compliance.

\section{CLINICAL EFFICACY IN ASTHMA}

The optimal place of LTRA in asthma management is still under review. This reflects their recent introduction and the relative paucity of fully published comparative studies, particularly compared with existing asthma treatments. For simplicity, in this article I will describe as first line treatment their use in studies in conjunction with "as required" short acting $\beta_{2}$ agonists. Their use in patients already receiving inhaled corticosteroids and "as required" short acting $\beta_{2}$ agonists will be described as second line treatment.

\section{First line treatment studies-chronic asthma}

LTRA $v$ PLACEBO

These studies are summarised in table $2 .{ }^{13-22}$ Most of the patients in these studies were steroid naive, and hence the description "first line treatment studies"; however, some did include a minority of patients receiving low dose inhaled corticosteroids or oral theophyllines, or both. ${ }^{13-16} 20$

Table 1 Prescribing information

\begin{tabular}{|c|c|c|}
\hline Generic name & Montelukast ${ }^{11}$ & Zafirlukast $^{12}$ \\
\hline Trade name & Singulair $^{\mathrm{TM}}$ & Accolate $^{\mathrm{TM}}$ \\
\hline Indications (UK) & $\begin{array}{l}\text { 1. Add on treatment in patients with mild to moderate persistent } \\
\text { asthma, inadequately controlled on inhaled corticosteroids and short } \\
\text { acting } \beta_{2} \text { agonists alone } \\
\text { 2. Exercise induced bronchoconstriction }\end{array}$ & Treatment of asthma \\
\hline Contraindications & $\begin{array}{l}\text { Acute asthma } \\
\text { Pregnancy / lactation } \\
\text { Severe hepatic impairment }\end{array}$ & $\begin{array}{l}\text { Acute asthma } \\
\text { Pregnancy / lactation } \\
\text { Hepatic impairment } \\
\text { Moderate to severe renal impairment }\end{array}$ \\
\hline Age group & $\begin{array}{l}>6 \text { years old } \\
\text { No dose adjustment in the elderly }\end{array}$ & $\begin{array}{l}>12 \text { years old } \\
\text { No dose adjustment in the elderly }\end{array}$ \\
\hline Formulation & Tablet (paediatric tablet chewable and cherry flavoured) & Tablet \\
\hline Dose & $\begin{array}{l}5 \mathrm{mg} \text { (if aged } 6-14 \text { years) } \\
10 \mathrm{mg} \text { (if }>14 \text { years) }\end{array}$ & $20 \mathrm{mg}$ \\
\hline Frequency & Once daily & Twice daily \\
\hline Special instructions & $\begin{array}{l}\text { Adult dose can be taken with food } \\
\text { Paediatric dose: avoid } 1 \mathrm{~h} \text { before and } 2 \mathrm{~h} \text { after meals }\end{array}$ & Avoid $1 \mathrm{~h}$ before and $2 \mathrm{~h}$ after meals \\
\hline Drug interactions & $\begin{array}{l}\text { None with oral contraceptive pill, warfarin, digoxin, theophylline, or } \\
\text { terfenadine } \\
\text { Coadministration with CYP 3A4 hepatic enzyme inducers (eg } \\
\text { phenytoin, phenobarbitone, rifampicin) may } \Downarrow \text { montelukast levels }\end{array}$ & $\begin{array}{l}\text { Patients on warfarin may have } \Uparrow \text { prothrombin times (monitor INR) } \\
\text { Aspirin may } \Uparrow \text { zafirlukast levels } \\
\Downarrow \text { Zafirlukast levels with erythromycin, terfenadine, theophylline }\end{array}$ \\
\hline
\end{tabular}



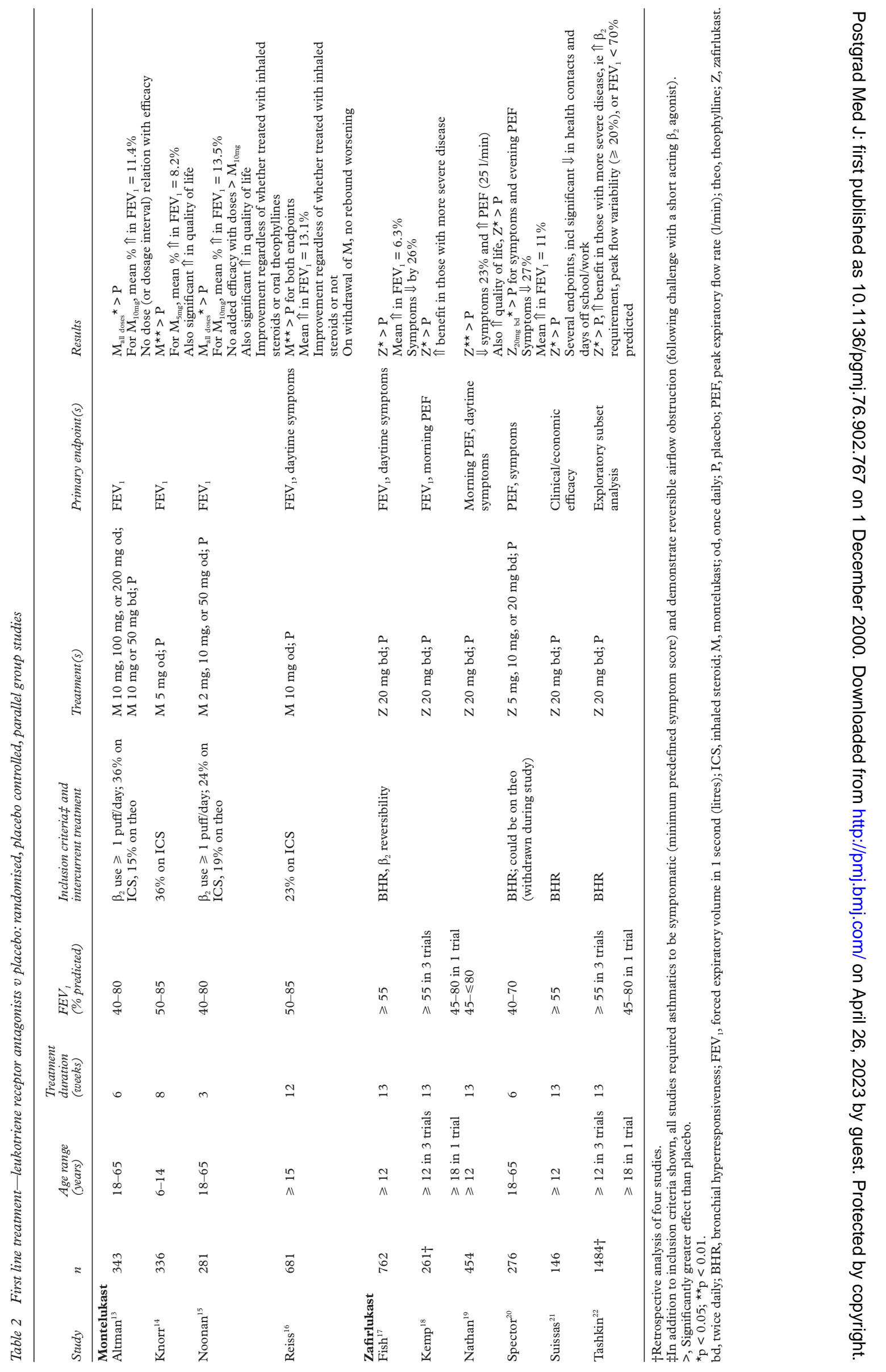
The primary endpoint in most of the studies was pulmonary function, usually forced expiratory volume in one second $\left(\mathrm{FEV}_{1}\right)$. Improvements in mean $\mathrm{FEV}_{1}$ were typically modest, for example $10 \%$, with much interindividual variation. Commonly used secondary endpoints included symptoms and quality of life scores, other measures of pulmonary function such as peak expiratory flow rates, the need for other drugs (short acting $\beta_{2}$ agonist or inhaled/ oral corticosteroid use), and effects on daily living (days off school or work). Improvement in these secondary outcomes was typically more impressive, for example $25 \%$. The majority of these studies concluded that the use of an LTRA in patients with mild asthma was superior to placebo, using these subjective and objective measures.

Only one of these studies examined use of LTRA in patients with more severe airflow obstruction. ${ }^{18}$ In this retrospective pooled subgroup analysis, data were reviewed from four clinical trials in which zafirlukast $20 \mathrm{mg}$ twice daily or placebo was given over a 13 week period to 261 steroid naive patients identified as having severe persistent asthma. Compared with placebo, patients receiving zafirlukast had significantly $(p<0.05)$ greater improvements in spirometry, peak expiratory flow, symptoms, and $\beta_{2}$ agonist requirement. However, these changes - although statistically significantwere small. Furthermore, given that current United Kingdom and American asthma management guidelines advise early use of an optimal dose of inhaled corticosteroids in patients with asthma of this severity, ${ }^{23}{ }^{24}$ this study is of limited clinical relevance.

LTRA $v$ INHALED CORTICOSTEROID

There is only one fully published study directly comparing use of an LTRA with low dose inhaled corticosteroid in patients with mild asthma. ${ }^{25}$

In this randomised, double bind, parallel group, multicentre study, 895 patients with mild to moderate asthma received montelukast $10 \mathrm{mg}$ once daily, $200 \mu \mathrm{g}$ of beclomethasone twice daily with a spacer, or placebo for three months. Both montelukast and beclomethasone were more effective than placebo, primary endpoints being daytime asthma symptoms and $\mathrm{FEV}_{1}$; montelukast had a faster onset of action (day 1) compared with beclomethasone (day 8). Nevertheless, patients receiving beclomethasone achieved a significantly better mean effect in terms of increased $\mathrm{FEV}_{1}$ and symptom reduction. For example, the average percentage change from baseline in $\mathrm{FEV}_{1}$ over three months was $13.1 \%$ with beclomethasone, $7.4 \%$ with montelukast, and $0.7 \%$ with placebo $(p<0.001$ for each active treatment compared with placebo; $p<0.01$ for beclomethasone compared with montelukast). It is interesting to note that both active treatment groups had a similar (normal) distribution of response, so it is incorrect to assume that patients are easily categorised into "responders" or "nonresponders" to either treatment. ${ }^{25}$
LTRA $v$ OTHER ASTHMA TREATMENTS

There is only one published study comparing an LTRA with sodium cromoglycate. ${ }^{26}$ This 13 week, randomised, parallel group study recruited 287 patients with mild to moderate asthma, comparing zafirlukast, sodium cromoglycate aerosol (1.6 mg four times daily), and placebo. No significant difference was detected between either of the active treatments, although both were better than placebo in terms of symptom improvement and reduced $\beta_{2}$ agonist use. Subset analysis suggested greatest improvement in patients with $\geqslant 10 \%$ peak flow variability. ${ }^{26}$

\section{Second line treatment studies-chronic asthma}

LTRA $v$ PLACEBO

Subgroup analysis of several studies mentioned earlier (table 2) suggested that montelukast could provide additional clinical benefit for patients using concomitant inhaled corticosteroids. ${ }^{13-16}$ This has now been confirmed prospectively in an important study by Laviolette et $a .^{27}$ In that study, 642 patients with chronic asthma incompletely controlled by inhaled beclomethasone $200 \mu \mathrm{g}$ twice daily with a spacer were randomised to one of four treatment groups: (1) montelukast $10 \mathrm{mg}$ once daily + continuing beclomethasone; (2) placebo tablet + continuing beclomethasone; (3) montelukast + inhaled placebo (after blind beclomethasone removal); and (4) placebo tablet and inhaler. The use of montelukast, in conjunction with $400 \mu \mathrm{g} /$ day beclomethasone dipropionate, provided significant additional benefit in terms of improving $\mathrm{FEV}_{1}$, daytime asthma scores, and nocturnal awakenings.

LTRA $v$ LONG ACTING $\beta_{2}$ AGONISTS

There is only one published study comparing these drug classes in chronic asthma. ${ }^{28}$ Salmeterol and zafirlukast were compared in a four week, randomised, double blind, parallel group multicentre study. Over $80 \%$ of the patients were having concomitant inhaled corticosteroid treatment, and received either inhaled salmeterol $42 \mu \mathrm{g}$ twice daily by metered dose inhaler or oral zafirlukast $20 \mathrm{mg}$ twice daily. The primary outcome measure was morning peak expiratory flow (PEF) rates. Both active treatments were associated with improvements from baseline in pulmonary function, asthma symptoms, and short acting $\beta_{2}$ agonist use. Salmeterol treatment resulted in significantly greater improvements from baseline compared with zafirlukast for most efficacy measures, including morning PEF (29.6 1/min $v 13.0$ $1 / \mathrm{min} ; \mathrm{p} \leqslant 0.01$ ), percentage of symptom-free days $(22.4 \%$ v $8.8 \%$; $\mathrm{p} \leqslant 0.01)$, and percentage of days and nights with no supplemental short acting $\beta_{2}$ agonist use $(30.5 \%$ v $11.3 \%$; $\mathrm{p} \leqslant 0.01)$. $^{28}$

These results, while in favour of salmeterol, are perhaps not surprising, as LTRA are recognised as being less potent bronchodilators than long acting $\beta_{2}$ agonists. The endpoint chosen in this short study is therefore very relevant when comparing these two drug classes. It may be that the presumed additional anti- 
inflammatory effects conferred by LTRA use (which may take several months to see) may be equally as important as improvements in spirometry.

LTRA $v$ OTHER ASTHMA TREATMENTS

There are few fully published studies comparing the use of alternative second line treatments such as theophyllines, long acting $\beta_{2}$ agonists, or cromones with LTRA. One study has suggested that combination treatment with montelukast and salmeterol confers additive benefits to patients who are suboptimally controlled on inhaled corticosteroids, in terms of bronchoprotection to adenosine challenge and bronchodilatation. ${ }^{29}$

LTRA AS STEROID SPARING AGENTS

Although not currently licensed for use in this way, two studies have addressed the potential role of LTRA as steroid sparing agents in patients requiring high maintenance doses of inhaled corticosteroids. ${ }^{3031}$ This is an important issue, particularly given concerns about the potential risk of systemic adverse effects associated with prolonged use of high dose inhaled corticosteroids.

In a randomised, double blind, placebo controlled study, 79 asthma patients (mean $\mathrm{FEV}_{1}$ $81 \%$ of predicted) requiring a mean daily dose of approximately $1900 \mu \mathrm{g}$ of beclomethasone dipropionate were studied. ${ }^{30}$ Following a two week run in phase, each patient's dose of beclomethasone was halved for six weeks. During this time, patients received additional treatment, either as placebo or as an LTRA (pranlukast, in a standard adult dose of $450 \mathrm{mg}$ twice daily). After six weeks, those receiving placebo had a significant deterioration in symptoms and lung function, combined with increased $\beta_{2}$ agonist requirement. Furthermore, this was mirrored by a rise in noninvasive markers of airway inflammation, including exhaled breath nitric oxide and blood eosinophil cationic protein. Interestingly, in the pranlukast group this subjective and objective deterioration was not seen, suggesting that use of an LTRA may facilitate dose reduction in patients dependent on high doses of inhaled corticosteroid, but not necessarily at the cost of an increase in airway inflammation. ${ }^{30}$

In another study of different design, the use of montelukast was also shown to facilitate a significant reduction in maintenance inhaled corticosteroid dose compared with placebo, over a period of 12 weeks. ${ }^{31}$ Studies longer than 12 weeks will obviously be necessary to see whether this is indeed a true steroid sparing effect.

\section{Exercise induced asthma}

Exercise induced bronchoconstriction is common in asthmatic patients, although the mechanisms underlying this are still poorly understood. ${ }^{32}$ Leukotrienes are recognised as important mediators associated with the reduction in airway calibre. Studies in both children $^{33} 34$ and adults ${ }^{35-39}$ have shown that LTRA afford substantial protection against exercise induced bronchoconstriction in many, but not all, patients with mild stable asthma. An advantage of LTRA in these patients is their duration of action. For example, protection against exercise induced bronchoconstriction is evident with montelukast even 20 to 24 hours after dosing. Furthermore, unlike long acting $\beta_{2}$ agonists, chronic dosing with LTRA is not associated with tolerance to their effects. ${ }^{40-42}$

\section{Aspirin induced asthma}

Aspirin induced asthma affects approximately $10 \%$ of adult patients with asthma. ${ }^{43}$ In these patients, exposure to aspirin and other cyclooxygenase inhibitors, for example nonsteroidal anti-inflammatory agents, is associated with excessive leukotriene release. Interestingly, bronchial biopsies from these patients show overexpression of leukotriene $\mathrm{C}_{4}$ synthase in eosinophils and mast cells (fig 1). ${ }^{44}$ This may be secondary to a common polymorphism of the $\mathrm{LTC}_{4}$ gene. ${ }^{45}$ Intuitively therefore, LTRA are a logical treatment choice in this type of asthma patient. Clinical efficacy has been demonstrated compared with placebo, even in patients already receiving inhaled corticosteroid treatment. ${ }^{11}$ It should be emphasised, however, that patients should still avoid ingestion of aspirin and related drugs, even if taking an LTRA, as protection is not complete. $^{46}{ }^{47}$

\section{Premenstrual asthma}

Many women describe an increase in asthma symptoms just before and during menstruation. ${ }^{48}$ While the mechanism remains unclear, one theory is that systemic mast cell activation occurs in response to altered female hormone levels, resulting in release of potent mediators including leukotrienes. Interestingly, a recent study supports this hypothesis, suggesting that use of an LTRA may be beneficial in these patients. ${ }^{49}$

\section{Safety}

Montelukast and zafirlukast were first marketed in the United Kingdom in February and July 1998, respectively. Up to the end of April 1999, 233000 prescriptions had been issued for montelukast and 17000 for zafirlukast. Both drugs remain under close observation, but appear to be generally well tolerated. Most side effects are mild, for example gastrointestinal disturbance, rashes, and fatigue (box 2)..$^{50}$

Some isolated cases of Churg-Strauss syndrome, a rare systemic vasculitis associated with asthma, have been reported, but it seems unlikely that LTRA are directly implicated..$^{51} \mathrm{~A}$ more likely explanation is that inhaled (high dose) or oral corticosteroid treatment in these patients may mask the underlying vasculitis. If steroid doses are reduced inappropriately, facilitated by use of LTRA, the underlying vasculitis may be revealed. It should be emphasised that LTRA are not currently licensed in order to allow dose reduction of either inhaled or oral corticosteroids. Clinicians should be suspicious if patients with asthma in these circumstances develop worsening asthma symp- 
Box 2: Safety of leukotriene receptor antagonists

- Generally well tolerated, side effect profile similar to placebo.

- Common side effects reported include gastrointestinal disturbance, rashes, fatigue.

- Report any side effects to Committee of Safety of Medicines using yellow card scheme.

- Rare cases of Churg-Strauss syndrome (see text)—caution if reducing maintenance inhaled or oral corticosteroid.

toms in association with marked serum eosinophilia ( $\left.>1.5 \times 10^{9} / 1\right)$ and signs of a systemic vasculitis such as non-blanching rash, cardiac complications, and peripheral neuropathy. ${ }^{52}$

\section{Clinical efficacy in conditions other than asthma}

Leukotriene receptor antagonists have been used successfully in a variety of other conditions, notably rhinitis, which often coexists in asthma patients. ${ }^{53-55}$ Other conditions have included atopic dermatitis ${ }^{56}$ and eosinophilic gastroenteritis. ${ }^{57}$ There is no evidence that the current cysteinyl leukotriene receptor antagonists will be useful in patients with chronic obstructive pulmonary disease.

\section{Predictors of response to LTRA}

Currently, it is not possible to predict who will respond well to an LTRA and, as described earlier, this response is normally distributed, so some patients (perhaps as many as $50 \%$ ) may have a disappointing response. Thus many clinicians opt for a four to eight week therapeutic trial of an LTRA, although longer trials may be necessary to detect beneficial effects in terms of attenuating airway inflammation. Recently, genetic polymorphisms of the enzymes controlling biosynthesis of leukotrienes have been described and may be important predictors of response. ${ }^{44} 455859$

\section{Place of LTRA in asthma management guidelines}

The current British Thoracic Society asthma management guidelines, published in 1997, are in need of updating, as leukotriene receptor antagonists only became available for prescription after that date. The current American guidelines, similarly published in 1997, do mention the LTRA zafirlukast and suggest that it may be an option as monotherapy in patients aged $\geqslant 12$ years or older with mild persistent asthma. Both guidelines acknowledge that the position of leukotriene receptor antagonists in current practice "is not fully established."

It seems likely that forthcoming United Kingdom guidelines will continue to advise early use of anti-inflammatory treatment in the form of low dose inhaled corticosteroid $(\leqslant 800$ $\mu \mathrm{g} /$ day of beclomethasone or equivalent), with LTRA reserved for second line use in those
Box 3: Leukotriene receptor antagonists: summary

- Novel class of chronic asthma treatment, available in tablet form.

- In UK, montelukast and zafirlukast are available for prescription.

- Combination of bronchodilator and anti-inflammatory properties.

- Rapid effects (days) and ease of administration may aid compliance.

- Useful in exercise induced and aspirin/NSAID induced asthma in particular.

- May be useful in other conditions, eg allergic rhinitis, atopic dermatitis.

patients who are still suboptimally controlled. New guidelines may also suggest that, in selected patients, monotherapy with an LTRA is still appropriate, particularly in patients with extremely mild disease reluctant to take inhaled corticosteroids, or in patients with aspirin induced or exercise induced symptoms. Acute asthma management guidelines are unlikely to advise the use of an LTRA, as there is no evidence to support their use in these patients.

1 Lipworth BJ. Leukotriene-receptor antagonists. Lancet 1999;353:57-62.

2 Drazen JM, Israel E, O'Byrne PM. Treatment of asthma with drugs modifying the leukotriene pathway. $N$ Engl F Med 1999;340:197-206.

3 Brocklehurst WE. The release of histamine and the formation of a slow reacting substance (SRS-A) during anaphylactic shock. F Physiol (Lond) 1960;151:416-35.

4 Murphy RC, Hammarstrom S, Samuelsson B. Leukotriene C. A slow reacting substance from murine mastocytoma cells. Proc Natl Acad Sci USA 1979;76:4275-79.

5 Dahlen SE, Hedqvist P, Hammarstrom S, et al. Leukotrienes are potent constrictors of human bronchi. Nature 1980;288:484-6.

6 Lynch KR, O'Neill GP, Liu Q, et al. Characterization of the human cysteinyl leukotriene CysLT 1 receptor. Nature 1999; 399:789-93.

7 Sarau HM, Ames RS, Chambers J, et al. Identification, molecular cloning, expression, and characterization of a cysteinyl leukotriene receptor. Mol Pharmacol 1999;56:65763.

8 Busse WW. Leukotrienes and inflammation. Am $\mathcal{F}$ Respir Crit Care Med 1998;157:S210-13.

9 Wardlaw AJ, Hay H, Cromwell O, et al. Leukotrienes, LTC4 and LTB4 in bronchoalveolar lavage in bronchial asthma and other respiratory diseases. F Allergy Clin Immunol 1989; 84:19-26.

10 Dworski R, Fitzgerald GA, Oates JA, et al. Effect of oral prednisone on airway inflammatory mediators in atopic asthma. Am 7 Respir Crit Care Med 1994;149:953-9.

11 Summary of product characteristics. Singulair. Hertfordshire, UK: Merck Sharp \& Dohme Ltd, January 1998.

12 Summary of product characteristics. Accolate. Cheshire, UK: Zeneca Ltd, July 1998.

13 Altman LC, Munk Z, Seltzer J, et al. A placebo-controlled, dose-ranging study of montelukast, a cysteinyl leukotriene receptor antagonist. Montelukast Asthma Study Group. $\mathcal{F}$ Allergy Clin Immunol 1998;102:50-6.

14 Knorr B, Matz J, Bernstein JA, et al. Montelukast for chronic asthma in 6- to 14-year-old children: a randomized, double-blind trial. $\mathcal{F} A M A$ 1998;279:1181-6.

15 Noonan MJ, Chervinsky P, Brandon M et al. Montelukast, a potent leukotriene receptor antagonist, causes dose-related improvements in chronic asthma. Montelukast Asthma Study Group. Eur Respir F 1998;11:1232-9.

16 Reiss TF, Chervinsky P, Dockhorn RJ, et al. Montelukast, a once-daily leukotriene receptor antagonist, in the treatment of chronic asthma : a multicentre, randomized, double-blind trial. Montelukast Clinical Research Study Group. Arch Intern Med 1998;158:1213-20.

17 Fish JE, Kemp JP, Lockey RF, et al. Zafirlukast for symptomatic mild-to-moderate asthma: a 13-week multicenter study. The Zafirlukast Trialists Group. Clin Ther 1997;19: study. The

18 Kemp JP, Minkwitz MC, Bonuccelli CM, et al. Therapeutic effect of zafirlukast as monotherapy in steroid-naive patients with severe persistent asthma. Chest 1999;115:336-42. 
19 Nathan RA, Bernstein JA, Bielory L, et al. Zafirlukast improves asthma symptoms and quality of life in patients with moderate reversible airflow obstruction. F Allergy Clin Immunol 1998;102:93

20 Spector SL, Smith LJ, Glass M. Effects of 6 weeks of therapy with oral doses of ICI 204,219, a leukotriene $\mathrm{D}_{4}$ receptor antagonist, in subjects with bronchial asthma. Med 1994;150:618-23.

21 Suissa S, Dennis R, Ernst P, et al. Effectiveness of the leukotriene receptor antagonist zafirlukast for mild-to-moderate asthma. A randomized, double-blind, placebo-controlled trial. Ann Intern Med 1997;126:177-83.

22 Tashkin DP, Nathan RA, Howland WC, et al. An evaluation of zafirlukast in the treatment of asthma with exploratory subset analyses. F Allergy Clin Immunol 1999;103:246-54.

23 British guidelines on asthma management; 1995 review and position statement. Thorax 1997;52:S1-21.

24 National Asthma Education and Prevention Program Expert Panel. National Asthma Education and Prevention Expert Panel. National Asthma Education and Prevention
Program Expert Panel report. II. Guidelines for the diagnosis Program Expert Panel report. II. Guidelines for the diagnosis and management of asthma. (Publication No 97-40

25 Malmstrom K, Rodriguez-Gomez G, Guerra J, et al. Oral montelukast, inhaled beclomethasone, and placebo for chronic asthma. A randomized, controlled trial. Montelukast/Beclomethasone Study Group. Ann Intern Med 1999;130:487-95.

26 Nathan RA, Minkwitz MC, Bonuccelli CM. Two first-line therapies in the treatment of mild asthma: use of peak flow variability as a predictor of effectiveness. Ann Allergy Asthma Immunol 1999;82:497-503.

27 Laviolette M, Malmstrom K, Lu S, et al. Montelukast added to inhaled beclomethasone in treatment of asthma. Am $\mathcal{F}$ Respir Crit Care Med 1999;160:1862-8.

28 Busse W, Nelson H, Wolfe J, et al. Comparison of inhaled salmeterol and oral zafirlukast in patients with asthma. $\mathcal{F}$ Allergy Clin Immunol 1999;103:1075-80.

29 Dempsey OJ, Wilson AM, Sims EJ, et al. Additive bronchoprotective and bronchodilator effects with single doses of protective and bronchodilator effects with single doses of salmeterol and montelukast in asthmatic patie

30 Tamaoki J, Kondo M, Sakai N, et al. Leukotriene antagonist prevents exacerbation of asthma during reduction of high-dose inhaled corticosteroid. The Tokyo Joshi-Idai Asthma Research Group. Am f Respir Crit Care Med 1997;155:1235-40.

31 Lofdahl CG, Reiss TF, Leff JA, et al. Randomised, placebo controlled trial of effect of a leukotriene receptor antagonist, montelukast, on tapering inhaled corticosteroids in asthmatic patients. BM尹 1999;319:87-90.

32 Hansen-Flaschen J, Schotland $\mathrm{H}$. New treatments for exercise-induced asthma. N Engl f Med 1998;339:192-3.

33 Kemp JP, Dockhorn RJ, Shapiro GG, et al. Montelukast once daily inhibits exercise-induced bronchoconstriction in 6- to 14-year-old children with asthma. F Pediatr 1998;133: 424-8.

34 Pearlman DS, Ostrom NK, Bronsky EA, et al. The leukotriene D4-receptor antagonist zafirlukast attenuates
exercise-induced bronchoconstriction in children. $\mathcal{F}$ Pediatr exercise-induced

35 Finnerty JP, Wood-Baker R, Thompson H, et al. Role of leukotrienes in exercise-induced asthma. Inhibitory effect of ICI 204 219, a potent leukotriene D4 receptor antagonist. Am Rev Respir Dis 1992;145:746-9.

36 Leff JA, Busse WW, Pearlman D, et al. Montelukast, a leukotriene-receptor antagonist, for the treatment of mild asthma and exercise-induced bronchoconstriction. $\mathrm{N} \mathrm{Engl} f$ Med 1998;339:147-52.

37 Reiss TF, Hill JB, Harman E, et al. Increased urinary excretion of LTE4 after exercise and attenuation of exerciseinduced bronchospasm by montelukast, a cysteinyl leukotriene receptor antagonist. Thorax 1997;52:1030-5.
38 Bronsky EA, Kemp JP, Zhang J, et al. Dose-related protection of exercise bronchoconstriction by montelukast, a cysteinyl leukotriene-receptor antagonist, at the end of a once-daily dosing interval Clin Pharmacol Ther 1997;62: 556-61.

39 Dessanges JF, Prefaut C, Taytard A, et al. The effect of zafirlukast on repetitive exercise-induced bronchoconstriction: The possible role of leukotrienes in exercise-induce refractoriness. F Allergy Clin Immunol 1999;104:1155-61.

40 Nelson JA, Strauss L, Skowronski M, et al. Effect of long-term salmeterol treatment on exercise-induced asthma. $N$ Engl f Med 1998;339:141-6.

41 Villaran C, O’Neill SJ, Helbling A, et al. Montelukast versus salmeterol in patients with asthma and exercise-induced bronchoconstriction. Montelukast/Salmeterol Exercise Study Group. F Allergy Clin Immunol 1999;104:547-53.

42 Edelman JM, Turpin JA, Bronsky EA, et al. Oral montelukast compared with inhaled salmeterol to prevent exercise-induced bronchoconstriction. A randomized, double-blind trial. Exercise Study Group. Ann Intern Med 2000;132:97-104.

43 Szczeklik A. Mechanism of aspirin-induced asthma. Allergy 1997;52:613-19.

44 Cowburn AS, Sladek K, Soja J, et al. Overexpression of leukotriene C4 synthase in bronchial biopsies from patients with aspirin-intolerant asthma. F Clin Invest 1998;101:8346.

45 Sanak M, Simon HU, Szczeklik A. Leukotriene C4 synthase promoter polymorphism and risk of aspirin-induced asthma. Lancet 1997;350:1599-600.

46 Menendez R, Venzor J, Ortiz G. Failure of zafirlukast to prevent ibuprofen-induced anaphylaxis. Ann Allergy Asthma Immunol 1998;80:225-6.

47 Enrique E, Garcia-Ortega P, Gaig P, et al. Failure of monteunkast to prevent anaphylaxis to diclofenac. Allergy 1999:54: 529-30

48 Gibbs CJ, Coutts II, Lock R, et al. Premenstrual exacerbation of asthma. Thorax 1984;39:833-6.

49 Nakasato H, Ohrui T, Sekizawa K, et al. Prevention of severe premenstrual asthma attacks by leukotriene receptor premenstrual althma attacks by leukotriene

50 Medicines Control Agency. Leukotriene receptor antagonists: update on adverse reaction profiles. Curr Probl Pharmacovigil 1999;25:14.

51 Stirling RG, Chung KF. Leukotriene antagonists and Churg-Strauss syndrome: the smoking gun. Thorax 1999; 54:865-6.

52 D'Cruz DP, Barnes NC, Lockwood CM. Difficult asthma or Churg-Strauss syndrome? BMF 1999;318:475-6.

53 Howarth PH. Leukotrienes in rhinitis. Am J Respir Crit Care Med 2000;161:S133-6.

54 Donnelly AL, Glass M, Minkwitz MC, et al. The leukotriene D4-receptor antagonist, ICI 204,219, relieves symptoms of acute seasonal allergic rhinitis. Am 7 Respir Crit Care Med. 1995;151:1734-9.

55 Pullerits T, Praks L, Skoogh BE, et al. Randomized placebocontrolled study comparing a leukotriene receptor antagonist and a nasal glucocorticoid in seasonal allergic rhinitis. Am $\mathcal{f}$ Respir Crit Care Med. 1999;159:1814-18.

56 Carucci JA, Washenik K, Weinstein A, et al. The leukotriene antagonist zafirlukast as a therapeutic agent for atopic dermatitis. Arch Dermatol 1998;134:785-6.

57 Neustrom MR, Friesen C. Treatment of eosinophilic gastroenteritis with montelukast [letter]. I Allergy Clin Immunol 1999;104:506.

58 Drazen JM, Yandava CN, Dube L, et al. Pharmacogenetic association between ALOX5 promoter genotype and the response to anti-asthma treatment. Nat Genet 1999;22:16870.

59 In KH, Asano K, Beier D, et al. Naturally occurring mutations in the human 5-lipoxygenase gene promoter that modify transcription factor binding and reporter gene transcription. F Clin Invest 1997;99:1130-7. 